\title{
Modular working for gastroenterology specialist registrars: delivering higher quality training and improved service provision
}

\author{
Authors: Phil Harvey, Edward Fogden, Saket Singhal, Mark Anderson and Nigel Trudgill
}

\section{Background}

Gastroenterology specialist registrars (SpRs) have competing demands on their time. Cover by all grades of trainees for inpatient ward work is often limited. General internal medicine (GIM) on-call frequency and subsequent 'off days' increased with the introduction of the 2016 contract. SpRs can therefore struggle to gain sufficient outpatient and endoscopy experience.

\section{Methods}

A new rota was designed for six SpRs including ward cover, outpatient attendance, endoscopy training and endoscopy service lists with separate periods of modular training when ward cover was undertaken. GIM on-call commitment remained unchanged. Outpatient attendance, endoscopy exposure and service provision were audited before and after the new rota was introduced.

\section{Results}

There were four SpRs on the previous rota before intervention including: two specialty year (St)7s, one St4 and one St 3 compared with the new rota with $4.4 \mathrm{SpRs}$, including: $1.8 \mathrm{St} 7 \mathrm{~s}, 0.6 \mathrm{St} 5 \mathrm{~s}$, one St 4 and one St3. In the previous rota trainees performed 16.8 endoscopies (7.3 colonoscopies, 9.5 gastroscopies) per SpR per month compared with 32.2 (16.1 colonoscopies, 16.1 gastroscopies) on the new rota. Service endoscopy increased numerically from six colons and six gastroscopies to nine colons and nine gastroscopies per SpR per month. Across a six SpR rota this represents 648 'points' of additional endoscopy activity per annum.

Clinic attendance was 3.3 and 3.2 per SpR per month on the previous and new rotas respectively. Projected clinic activity with improved booking efficiency was estimated at 20 additional outpatient clinics per month. Consistency of inpatient ward cover was also anecdotally challenging.

\section{Discussion}

The newly introduced modular rota led to a dramatic increase in outpatient endoscopy activity with both training and service benefits. Due to the complexity of the rota, optimal outpatient booking was challenging. Further PDSA (Plan, Do, Study, Act) cycles are planned to optimise this and inpatient ward cover. 